\title{
Adolescent Sexual and Reproductive Health Care Service Availability and delivery in Public Health Facilities of Plateau State Nigeria
}

\author{
Esther Awazzi Envuladu ( $\square$ esvula@yahoo.com ) \\ University of Jos https://orcid.org/0000-0002-4288-9587 \\ Karlijn Massar \\ Maastricht University \\ John de Wit \\ Utrecht University
}

\section{Research article}

Keywords: Adolescent Sexual and Reproductive Health Care Service, Public Health Facilities of Plateau State Nigeria, health care availability

Posted Date: August 25th, 2020

DOI: https://doi.org/10.21203/rs.3.rs-60029/v1

License: (c) (i) This work is licensed under a Creative Commons Attribution 4.0 International License. Read Full License

Version of Record: A version of this preprint was published at International Journal of Environmental Research and Public Health on February 3rd, 2021. See the published version at https://doi.org/10.3390/ijerph18041369. 


\section{Abstract}

To assessed the availability, accessibility, appropriateness and quality of ASRH services in Primary health care facilities in Plateau State, Nigeria, a cross sectional study was conducted in 230 PHCs across the three senatorial zones of Plateau state. Primary data was obtained through face to face interview with heads of facilities from December 2018 to May 2019 using an adapted questionnaire from WHO with five domains ascertaining the extent that ASHR services were available and provided. The questionnaires were administered to the head of the facilities. Very few PHCs in the state had space (1.3\%) and equipment (12.2\%) for ASRH services. The proportion of PHCs offering counselling on sexuality was $11.3 \%$, counselling on safe sex was $17 \%$, counselling on contraception was $11.3 \%$, and management of gender based violence was $3 \%$. Most facilities were not operating at convenient time for adolescents. Only $2.6 \% \mathrm{PHCs}$ had posters targeted at ASRH and just $7 \%$ of the PHCs had staff trained on ASRH. It was concluded that majority of the PHCs surveyed in Plateau State Nigeria lacked dedicated space, basic equipment and essential sexual and reproductive health care services for ASRH

\section{Background}

Adolescents worldwide, including in sub-Saharan Africa, are known to engage in sexual behaviors that place them at risk of adverse sexual and reproductive health outcomes, such as condom less sex and multiple sexual partners. ${ }^{1}$ Despite a declining trend in HIV incidence globally, the HIV infection rate remains high among adolescents in sub-Saharan Africa, including Nigeria. ${ }^{1,2}$ Some studies have reported HIV prevalence of $14-17 \%$ among adolescents in Nigeria, and the prevalence of other sexually transmissible infections (STIs) among adolescents has been found to range from $29-48.8 \%$ in different parts of the country. $3,4,5$

In addition to increased risk of infection with HIV and other STIs, condom less sex is also related to the high rates of teenage pregnancy that are reported in most sub-Saharan African countries. ${ }^{6,7,8}$ A systematic review of evidence from 52 African countries reported an overall pooled adolescent pregnancy rate of $18.8 \%$, and a pregnancy rate of $19.3 \%$ in sub-Saharan African countries. ${ }^{9}$ This is similar to the pregnancy rate of $17 \%$ reported among adolescent girls in Plateau state, Nigeria which is the region of focus in the current research as well. ${ }^{10}$ In most instances, adolescent pregnancies in Nigeria end in termination, despite the illegality of abortion. Nigeria records a yearly rate of 25 abortions per 1000 women, ${ }^{11,12}$ and a study conducted in the southern part of the country reported that $32 \%$ of these illegal, and often unsafe, abortions occur among adolescents girls. ${ }^{12}$ There is also evidence that some of these abortions are carried out by the adolescents girls themselves, using various dangerous local concoctions to terminate pregnancy. ${ }^{12,13}$ In most cases, these girls end up with serious complications while some die in the process, adding to the burden of maternal mortality in the country.

Furthermore, teenage pregnancies that are not terminated are associated with maternal reproductive risks for the teenage mother, since they are at higher risk of pre-eclampsia and eclampsia, antepartum hemorrhage and feto pelvic disproportion, as well as obstructed labor and its sequelae, notably genital fistulae. Teenage pregnancy also contributes significantly to maternal mortality rates. ${ }^{14}$ Furthermore, there are also potential social and psychological consequences for these girls. For example, teenage pregnancies in lower and middle income countries can and often do end in child marriage, whereby girls are forced to marry the men responsible for the pregnancy. ${ }^{15}$ Indeed, unintended pregnancy has been identified as a main reason for child marriage in Nigeria, ${ }^{16}$ and most married adolescents girls drop out of school, thereby becoming educationally and economically disadvantaged. ${ }^{17}$

There is thus a clear need to reduce the risk of HIV and STIs as well as teenage pregnancy among adolescents in Nigeria. The World Health Organization (WHO) notes that availability and access to quality sexual and reproductive health (SHR) information and services for adolescents is essential to reduce STI/HIV infections and teenage pregnancies. ${ }^{18}$ The provision of these services therefore seems essential for Nigerian adolescents as well. However, although family planning and maternal health care services are provided in health facilities across Nigeria, these are often adult-centered and not specific to adolescents' needs. ${ }^{19,20}$ Indeed, this lack of appropriate reproductive and sexual health care for adolescents is rapidly emerging as a public health concern in Nigeria, especially given the serious sexual and reproductive health risks adolescents face. ${ }^{20,21}$

To meet the WHO recommendations, the Nigerian government has introduced a policy to address the lack of adolescent-friendly sexual and reproductive health (ASRH) services in health facilities, especially in primary health care facilities, which are the first point of call and the nearest health facilities in communities ${ }^{22}$. The aim of this policy is to integrate ASRH services into primary health care facilities, to ensure the availability, accessibility, appropriateness, and quality of ASRH in Nigeria. However, despite the existence of this policy, it appears these services are not yet provided as intended. Notably, the findings from an earlier study we conducted in Plateau state, Nigeria, ${ }^{23}$ showed that adolescents experienced various SRH challenges, including poor knowledge of SRH and poor health seeking behaviour. Also, majority of adolescents in that study indicated they did not seek SRH services in health facilities, due to the absence of the services they required, an experienced lack of confidentiality, or negative attitudes of health care providers. ${ }^{23}$

Page $2 / 11$ 
Extending our earlier research on the sexual behaviour, SRH challenges of adolescents and factors influencing the health seeking behaviour of adolescents, the objective of this study is to contribute to an assessment of the state of implementation of the national reproductive health policy for adolescents in Nigeria. Specifically, the aim was to assess the current provision of comprehensive ASRH services in primary health care facilities in Plateau State, Nigeria and to compare if there are any differences across the senatorial zones. This is because of the variation in the settings, the Northern zone is considered to be an urban zone, the Central zone is semi-urban and the Southern zone could be said to be rural. To assess the ASRH services, we drew on the WHO guidelines for youth friendly health care services, ${ }^{24}$ that underscore the importance of ascertaining the extent to which the ASHR services are available, accessible, appropriate, and of sufficient quality as determinants to the effective utilization of the services by adolescents in Plateau State.

\section{Methods}

\section{Study setting and sampling}

This study was conducted in 230 public primary health care facilities (PHC) in six Local Government Areas (LGA) in Plateau State, Nigeria. This state consists of a total of 17 LGA across three senatorial zones; The Northern zone has six LGAs, the Central zone has five LGA's and the Southern zone consists of six LGAs. We selected health facilities in two stages. Firstly, two LGAs were selected from each of the three senatorial zones, using a simple random sampling technique. Secondly, we identified and included all the PHCs that provide services in the selected LGAs while the PHCs that no longer provide services were excluded from the study.

The Cochran formula $\left(n_{0}=Z^{2} \mathrm{pq} / \mathrm{e}^{2}\right)$ was used to calculate the sample size of health facilities to be included in the study. ${ }^{25}$ The margin of error (e) for the sample size calculation was set at $5 \%$, and the proportion of primary health facilities in each zone providing ASRH services $(p ; q=1-p)$ was set at $50 \%$, equivalent to the national policy target. After applying the correction for smaller population sizes $\left(n f=n_{0} / 1+\left(n_{0}{ }^{-}\right.\right.$ 1)/N), the estimated required sample size was 217 facilities but eventually assessed 230 facilities

\section{Data collection}

A cross sectional survey was conducted in all the included PHCs in the six selected LGAs across the three senatorial zones of Plateau state. Each participating PHC was visited by the research team which consisted of the first author and ten research assistants who administered the survey questionnaires to the heads of the facilities. Seven of the research assistants were resident doctors and three were community health workers. Team members were all trained before data collection commenced, and could speak English, Hausa, and the common dialect in the study areas. A mapping of the number, the locations and distance between the PHC in each LGA was done to enable smooth logistics, considering that some PHCs are more than $5 \mathrm{~km}$ from the main access road.

In addition to basic information, such as senatorial zone and LGA, the names and location of the health facilities were recorded. Further, we assessed the availability of space and equipment for ASRH, availability of specific ASRH services, accessibility of ASRH services, appropriateness of ASRH services, and quality of ASRH services. The assessment of ASRH was based on the WHO guidelines for youth friendly health service. ${ }^{24}$ The survey questionnaire was pre-tested in Jos South LGA, an LGA that was not included in the selected 6 LGAs in which study data were collected.

Several questions were asked to assess each of the factors, as detailed below. The responses to each question were dichotomized, whereby affirmative responses (e.g., item is present, available, provided, carried out) were scored 1, whereas negating responses (e.g., item is not present, not available, not provided, not carried out) were scored 0 .

Availability of ASRH space and equipment was assessed with five items regarding the availability of a dedicated ASRH waiting area, a dedicated space for ASRH consultation, a dedicated area for ASRH counselling, a dedicated ASRH examination room and ASRH specific equipment (e.g appropriate size speculum).

Availability of ASRH services was assessed with nine items regarding the provision of counselling on sexuality, prevention of pregnancy/contraception, safe sex/STI prevention and gender based violence (GBV), as well as the management of GBV, voluntary counselling and testing(VCT) for HIV, and post-abortion care.

Accessibility of ASRH services was assessed with four items regarding distance of the facility from the main road, distance from places in the locality where adolescents gather, distance from school in the locality, and opening/closing hours of the PHCs.

Appropriateness of ASRH services was assessed based on the availability of specific clinic hours for adolescent consultations, availability of posters and other ASRH educational materials, the availability of dedicated ASRH peer education staff, the provision of outreach services for adolescents, and the availability of ASRH services without parental consent. 
Quality of ASRH services was assessed with three items regarding the availability of guidelines for provision off ASRH services, whether staff were trained on ASRH and the availability of referrals to specialized services if necessary.

\section{Data analysis}

Data were analysed using SPSS version 23. For each of the three senatorial zones, we first computed the proportion of PHC responding affirmatively to each of the items pertaining the various domains of the adapted WHO guideline for ASRH (i.e, availability of space and equipment, availability of ASRH services, accessibility of ASRH services, appropriateness of ASRH services and quality of ASRH services). For each domain, we also established if a PHC responded affirmatively to all items, reflecting that PHC met all criteria for that domain. We also compared the proportions of PHCs across the three senatorial zones that responded affirmatively to specific items per domain using chi-square tests or Fisher's exact tests, as appropriate. Furthermore, for each of the domains we compared the observed proportions of PHC per senatorial zone that met all criteria to the target of the National Sexual and Reproductive Health Policy stipulating that at least $50 \%$ of PHC should provide comprehensive ASRH services.

\section{Patient and public involvement}

No patient involved

\section{Ethical considerations}

Ethical approval was obtained from the Jos University Teaching Hospital Human Research and Ethics Committee with ref number JUTH/DCS/ADM/127/XXVIII/1187 before commencement of the study. Permission to undertake the research was also obtained from the Ministry of Health as well as from the chair persons of all LGAs. At each PHC facility, written informed consent was obtained from the officer who completed the questionnaire.

\section{Results}

\section{Overall adolescent friendliness of SRH services}

The findings from this study shows that the entire state has not met the criteria for adolescent friendly SRH service as stated in the policy. As shown in Table 1, the domains of ASRH all received a poor score, indicating that across facilities substantially lower services than recommended within the policy are being provided. For example, in the Northern zone, only $17.8 \%$ of PHCs had sufficient availability of ASRH services while in the Central Zone, only $13,5 \%$ of the facilities had ASRH services and the Southern zone with the highest score, only had $22.8 \%$ facilities provided the recommended level of care. The difference in the scoring for all the domains was not statistically significant $(p=0.630)$

Table 1 proportion of health facilities per senatorial zone meeting all criteria for domains of adolescent friendly health services.

\begin{tabular}{|llllll|}
\hline Domains of adolescent friendly service & \multicolumn{2}{l}{ Senatorial zones } & & 口 & p-value \\
\hline & Northern & Central & Southern & & \\
\hline Availability of structure for ASRH & $7.6 \%$ & $5.4 \%$ & $10.1 \%$ & 1.652 & 0.44 \\
\hline Availability of services for ASRH & $17.8 \%$ & $13.5 \%$ & $22.8 \%$ & 2.218 & 0.33 \\
\hline Accessibility of ASRH services & $45.5 \%$ & $50 \%$ & $55.3 \%$ & 0.808 & 0.67 \\
\hline Appropriateness of ASRH services & $10.2 \%$ & $6.5 \%$ & $13 \%$ & 1.800 & 0.41 \\
\hline Quality of ASRH services & $25.3 \%$ & $22.6 \%$ & $28.2 \%$ & 0.500 & 0.78 \\
\hline Overall & $21.3 \%$ & $19.6 \%$ & $25.9 \%$ & 0.925 & 0.63 \\
\hline
\end{tabular}

\section{Availability of ASRH space and equipment}

With regards to the availability of dedicated space and equipment for ASRH, the results shown in Table 2 highlight that very few PHC facilities in the entire state had a dedicated waiting area or consultation space for adolescent ASRH. Further, only about one in ten facilities had a specific counselling area, and only just over one in ten facilities had a dedicated examination room for ASRH and equally just over one in ten facilities had dedicated equipment for ASRH. There was no significant differences across the senatorial zones in terms of the proportion of facilities that had any dedicated space for ASRH service delivery, dedicated waiting area for $\mathrm{ASRH}$, or dedicated ASRH 
equipment. There were however significant difference between senatorial zones with respect to the availability of a dedicated ASRH counselling area and examination room. The southern zone had a significantly higher number of facilities with dedicated counselling areas than other zones, while facilities in the central zone were significantly less likely to have dedicated ASRH examination rooms. See Table 2 for an overview

Table 2

proportion of health facilities per senatorial zone with dedicated ASRH space and equipment

\begin{tabular}{|llllll|}
\hline Space/equipment & \multicolumn{2}{l}{ Senatorial zones } & & p-value \\
\hline & Northern & Central & Southern & Total & \\
\hline Space for ASRH Available & $1(1.5 \%)$ & $1(1.1 \%)$ & $1(1.4 \%)$ & $3(1.3 \%)$ & 0.97 \\
\hline Counselling area Available & $5(7.6 \%)$ & $5(5.4 \%)$ & $12(16.9 \%)$ & $22(9.6 \%)$ & 0.04 \\
\hline Examination room Available & $11(16.7 \%)$ & $5(5.4 \%)$ & $11(15.5 \%)$ & $27(11.7 \%)$ & 0.05 \\
\hline Waiting room Available & $3(4.5 \%)$ & $1(1.1 \%)$ & $0(0 \%)$ & $4(1.7 \%)$ & 0.10 \\
\hline Equipment Available & $5(7.6 \%)$ & $13(14 \%)$ & $10(14.1 \%)$ & $28(12.2 \%)$ & 0.40 \\
\hline
\end{tabular}

\section{Availability of ASRH services}

The availability of seven ASRH counselling services was assessed: counselling for sexuality, counselling on contraception, counselling on $\mathrm{STI} /$ safe sex, counselling on GBV, management of GBV, counselling on VCT, and post abortion care. The results showed counselling on safe sex was least likely to be provided in the central zone, more likely in the Northern zone, and most likely to be provided in the Southern zone. Post abortion care was also least provided in the central zone, more in the Northern zone and most likely provided in the Southern zone, however, all the items assessed under availability of services were poorly provided across the three senatorial zones. For an overview, see Table 3.

Table 3

proportion of health facilities per senatorial zone with dedicated ASRH services

\begin{tabular}{|c|c|c|c|c|c|}
\hline \multirow[t]{2}{*}{ Services available } & \multicolumn{4}{|c|}{ Senatorial zones } & \multirow[t]{2}{*}{ p-value } \\
\hline & Northern & Central & Southern & Total & \\
\hline Counselling on sexuality Carried out & $8(12.1 \%)$ & $7(7.5 \%)$ & $11(15.5 \%)$ & $26(11.3 \%)$ & 0.27 \\
\hline $\begin{array}{l}\text { Counselling on Contraception } \\
\text { Done }\end{array}$ & $7(10.6 \%)$ & $7(7.5 \%)$ & $12(16.9 \%)$ & $26(11.3 \%)$ & 0.17 \\
\hline $\begin{array}{l}\text { Counselling on STI } \\
\text { Done }\end{array}$ & $11(16.7 \%)$ & $13(14 \%)$ & $19(26.8 \%)$ & $43(18.7 \%)$ & 0.10 \\
\hline $\begin{array}{l}\text { Counselling on safe sex } \\
\text { Done }\end{array}$ & $12(18.2 \%)$ & $9(9.7 \%)$ & $18(25.4 \%)$ & $39(17 \%)$ & 0.03 \\
\hline $\begin{array}{l}\text { Counselling on GBV } \\
\text { Done }\end{array}$ & $4(6.1 \%)$ & $6(6.5 \%)$ & $8(11.3 \%)$ & $18(7.8 \%)$ & 0.43 \\
\hline $\begin{array}{l}\text { Management of GVB } \\
\text { Done }\end{array}$ & $1(1.5 \%)$ & $2(2.2 \%)$ & $4(5.6 \%)$ & $7(3 \%)$ & 0.30 \\
\hline $\begin{array}{l}\text { Counselling on VCT } \\
\text { Done }\end{array}$ & $41(62.1 \%)$ & $52(55.9 \%)$ & $37(52.1 \%)$ & $130(56.5 \%)$ & 0.49 \\
\hline $\begin{array}{l}\text { Post abortion care } \\
\text { Provided }\end{array}$ & $5(7.6 \%)$ & $2(2.2 \%)$ & $11(15.5 \%)$ & $18(7.8 \%)$ & 0.01 \\
\hline
\end{tabular}


With regards to the accessibility of the health facilities and services, the results shows that less than half of the facilities in the three senatorial zones were located near the main road, and more than half of the facilities across the zones were situated close to places where adolescents gather in the locality and where schools were located. However, less than half of the facilities in the three zones had opening and closing hours that were convenient for adolescents (see Table 4 for an overview).Specifically, more than half of the facilities in the three senatorial zones were located in areas accessible to adolescents but less than $50 \%$ of the facilities in the three zones had operating hours that were convenient for adolescents. This was however significantly better $(p=0.021)$ in the southern zone (45.1\%) compared to northern zone (30.3\%) and the central zone (24.7\%).

Table 4

proportion of health facilities per zone with ASRH services that are accessible

\begin{tabular}{|c|c|c|c|c|c|}
\hline \multirow[t]{2}{*}{ Access } & \multicolumn{4}{|c|}{ Senatorial zones } & \multirow[t]{2}{*}{ p-value } \\
\hline & Northern & Central & Southern & Total & \\
\hline $\begin{array}{l}\text { Distance of HF from main road } \\
\text { Close }\end{array}$ & $27(40.9 \%)$ & $37(39.8 \%)$ & $34(47.9 \%)$ & $98(42.6 \%)$ & 0.55 \\
\hline $\begin{array}{l}\text { Distance of HF from where } \\
\text { Adolescents gather } \\
\text { Close }\end{array}$ & $37(56.1 \%)$ & $63(67.7 \%)$ & $45(63.4 \%)$ & $145(63 \%)$ & 0.32 \\
\hline $\begin{array}{l}\text { Distance from school } \\
\text { In locality } \\
\text { Close }\end{array}$ & $36(54.5 \%)$ & $63(67.7 \%)$ & $46(64.8 \%)$ & $145(63 \%)$ & 0.22 \\
\hline $\begin{array}{l}\text { Opening/closing hour } \\
\text { Close }\end{array}$ & $20(30.3 \%)$ & $23(24.7 \%)$ & $32(45.1 \%)$ & $75(32.6 \%)$ & 0.02 \\
\hline
\end{tabular}

\section{Appropriateness of ASRH services}

Overall, the SRH services in the state were generally not appropriate for adolescents (see Table 5), and all three zones scored poorly. Only $4.3 \%$ PHCs had separate hours for adolescents, $2.6 \%$ had posters as educational materials targeted at ASRH, peer educators were found in $3.9 \%$ PHCs and only $1.7 \%$ of the PHCs organized outreaches for adolescents once in a while in the State. Only one (1.5\%) facility in Northern zone, three (3.2\%) facilities in Central zone, and two (2.8\%) facilities in Southern zone had educational material like posters for adolescents. The southern zone however had a significantly higher number of peer educator staff $(p=0.01)$ and were more likely to provide ASRH services without parental consent $(p=0.03)$. 
Table 5

Services appropriate for adolescents

\begin{tabular}{|c|c|c|c|c|c|}
\hline \multirow[t]{2}{*}{ Services } & \multicolumn{4}{|c|}{ Senatorial zones } & \multirow[t]{2}{*}{ p-value } \\
\hline & Northern & Central & Southern & Total & \\
\hline $\begin{array}{l}\text { Specific clinic hours for adolescents } \\
\text { Yes }\end{array}$ & $3(4.5 \%)$ & $5(5.4 \%)$ & $2(2.8 \%)$ & $10(4.3 \%)$ & 0.73 \\
\hline $\begin{array}{l}\text { Availability of posters } \\
\text { Yes }\end{array}$ & $1(1.5 \%)$ & $3(3.2 \%)$ & $2(2.8 \%)$ & $6(2.6 \%)$ & 0.79 \\
\hline $\begin{array}{l}\text { Dedicated Peer education staff } \\
\text { Available }\end{array}$ & $1(1.5 \%)$ & $1(1.1 \%)$ & $7(9.9 \%)$ & $9(3.9 \%)$ & 0.01 \\
\hline $\begin{array}{l}\text { Organized Outreach services } \\
\text { Yes }\end{array}$ & $2(3 \%)$ & $0(0 \%)$ & $2(2.8 \%)$ & $4(1.7 \%)$ & 0.25 \\
\hline Services offered without parental consent & $31(47 \%)$ & $27(29 \%)$ & $32(45.1 \%)$ & $90(39.1 \%)$ & 0.03 \\
\hline Yes & $0(0 \%)$ & $0(0 \%)$ & $0(0 \%)$ & $0(0 \%)$ & 0.73 \\
\hline QUALITY OF ASRH CARE SERVICES & $5(7.6 \%)$ & $5(5.4 \%)$ & $6(8.5 \%)$ & $16(7 \%)$ & 0.18 \\
\hline Guideline for ASRH & $45(68.2 \%)$ & $58(62.4 \%)$ & $54(76.1 \%)$ & 157(68.3) & \\
\hline Present & & & & & \\
\hline Staff trained on ASRH & & & & & \\
\hline Trained staff & & & & & \\
\hline Referrals made & & & & & \\
\hline Yes & & & & & \\
\hline
\end{tabular}

\section{Quality of ASRH services}

The quality of ASRH services was scored as poor across the three senatorial zones: there were no guidelines for ASRH service delivery, and training of staff was very poor in the State with only $7 \%$ of the PHCs employing staff trained for ASRH. The Southern zone had the highest number of staff trained on ASRH (8.5\%), the difference was however not statistically significant $(p=0.73)$. More than half $(68.3 \%)$ of the PHCs refer adolescents to secondary health facilities for treatment.

\section{Discussion}

One of the most critical and arguably fundamental areas of meeting the sexual and reproductive health needs of adolescents is the provision of a comprehensive adolescent-friendly sexual and reproductive health care service in health facilities. Most adolescents are in need of various SRH services and studies in Nigeria and India have shown they at times self-medicate or go to unqualified providers for help and may risk their health and lives as a result of unsafe practices. ${ }^{23,26}$ Many reasons have been given for this concerning state of affairs with the extent of preparedness of health facilities to offer ASRH services critical to the utilization of the services by adolescents, and ultimately to the reduction and prevention of unintended teenage pregnancies and maternal mortality which are unacceptably high in Nigeria, ${ }^{27}$ as well as reduction of STI and HIV infections among adolescents. ${ }^{19}$ The aim of the current research was to assess the provision of ASRH services in health facilities in Plateau State, Nigeria, in the light of the national policy which entails that ASRH be integrated into PHC facilities across the country.

For SRH services to be adolescent friendly, several factors must be considered according to WHO guideline; availability of dedicated space and equipment for ASRH, availability of specific ASRH services, accessibility of ASRH services, appropriateness of ASRH services and the quality of ASRH services. The results of the assessment reported in this study revealed that overall, Plateau State is not meeting the minimum standard requirement for the provision of ASRH services. Overall, the PHCs across the three senatorial zones did not meet the 
affirmative criteria of the five domains. The national target of 50\% PHCs providing adolescent-friendly SRH services was only met for the accessibility of ASRH in the central and southern zones, with the northern zone approaching this target. Similar results were seen in a survey conducted in other parts of Nigeria where health facilities had no dedicated space and equipment for ASRH and the facilities did not provide specific ASRH services

This finding is also in line with results of an assessment of adolescent and youth friendly health services in PHCs in two provinces in South Africa using a similar approach, which found that none of the primary health care facilities met the guideline standard for providing adolescent and youth friendly services. ${ }^{28}$ In the present research, majority of the PHCs across the three zones did not meet basic requirements for provision of ASRH services. Facilities that were sampled in this study generally lack space and equipment for ASRH. For example, many of the facilities did not have dedicated space for consultation with adolescents, no waiting rooms to separate adult clients from adolescents and no dedicated examination rooms for adolescents. The equipment were all adult sizes, they lacked sphygmomanometer with the cuff for adolescents and no adolescent size speculum for vagina examination. Traditionally, health facilities in Nigeria are designed for adults, with no consideration for adolescents: Many of the facilities lack separate spaces for adolescents, no waiting room to separate adult clients from adolescents and no separate examination room for adolescents. ${ }^{21,22}$

The provision of essential ASRH services was below the benchmark stipulated by the national policy. Very few PHCs in the three zones offer critical ASRH services such as counselling on sexuality, counselling on contraception, and counselling on safe sex/ STI prevention. Although family planning services were available in most facilities, these are usually not targeted at adolescents but married women. Generally, counselling on HIV testing scored above $50 \%$ across the zones. This is not surprising following the Government focus on HIV prevention and treatment which has driven so many non-governmental organizations to provide services targeted at HIV prevention in most facilities. This finding is a reflection of the assessment of youth friendly health services conducted in Nigeria, which also found that specific ASRH services such as counselling on safe sex and provision of contraceptive for adolescents were either not done or poorly provided in centres designated to do so. ${ }^{23,24}$ The worst of the services provided was that of counselling on gender base violence, probably because it is not recognized as a reproductive health problem but rather a domestic issue that should be handled privately at home.

Similar findings of low ASRH services were reported in a Ugandan and South African research, where specific ASRH services were poorly provided, except VCT for HIV that was fairly provided. ${ }^{20,22}$ When ASRH services were compared across the zones, the southern zone had better scores in counselling for safe sex and post abortion care but the reason for the difference was not established in this study. It may probably be because the southern zone is more of a rural area, and perhaps the assumption that such areas are more in need of SRH care services, thereby attracting the concentration of some NGOs in that region.

The government of Nigeria has admitted in the national Policy ${ }^{22}$ that adolescent and Youth Friendly services are an integral part of the PHC System. These services should however be accessible to those who need it, while it was observed that most of the facilities were situated close to schools and where adolescents gather in the localities, which should have been a strength and opportunity to leverage on in reaching out to adolescents, that was not the case, as it was discovered that the opening and closing hours were not suited to adolescents' needs in majority of the facilities. The facilities did not operate at hours convenient for adolescents (e.g. after school), and had no separate hours for adolescent counselling. Again, the Southern zone did significantly better in this area compared to the other zones but still below $50 \%$. Studies have demonstrated that adolescents have preferred hours for visiting health facilities, usually when adults are not around because of privacy and confidentiality. ${ }^{15,28}$ they usually will not like to discuss their sexual issues where adults will hear. Indeed, the lack of privacy was reported in Tanzania as one of the reasons for poor utilization of health facilities especially for SRH services by adolescents. ${ }^{15}$, 29

One important approach to meeting the SRH needs of adolescents is through health education carried out by health care providers, this was lacking in almost all the PHCs. There were no appropriate SRH health education materials like posters, no peer educators and therefore peer education was not done in most of the facilities. Once more, this was better done in the Southern zone compared to the others. Outreach services have been identified as an approach with great impact in meeting adolescent with SRH services bearing in mind that they value confidentiality and most will not want their parents to know they access such services. ${ }^{30,31,32}$ Unfortunately, not many health facilities across the state were utilizing the opportunity, despite the proximity of the health facilities to adolescents.

It is important that the health care providers are knowledgeable about ASRH and that there is a standard policy guideline to enable quality delivery of information and services to adolescents. Unfortunately, this was lacking across the three senatorial zones. Very few facilities had staff trained specifically on delivery of ASRH especially in the central zone. This scenario was also reported in the studies conducted in Tanzania and Nepal where lack of qualified staff affected the utilization of SRH services. ${ }^{30,33,34,35}$ Achieving a meaningful reduction in adolescent sexual and reproductive health challenges faced by the country will require an urgent intervention in the area of training of health 
care providers which should be backed with a standard management guideline and procedure that should be available in all the health care facilities

Although it is argued that the health system component is not the only aspect affecting the sexual and reproductive health of adolescents, the lack of such structure contributes to the poor sexual and reproductive health challenges of adolescents in Nigeria.

This study was just limited to public primary health care facilities and did not explore the private health facilities, perhaps some private health facilities may have ASRH friendly services in place. It would have been more holistic to assess all categories of health facilities.

\section{Conclusion}

This study revealed that majority of the public primary health care facilities that were surveyed in this study, lack basic structure, equipment, and essential sexual and reproductive health care services for adolescents. A few of the PHC facilities especially in the Southern zone provided counselling area for adolescents and also provided SRH services such as counselling on safe sex and prevention of pregnancy. While about half of the facilities were situated around schools and where adolescents gather. Activities like outreaches to meet and provide SRH services for adolescents were not carried out in most of the facilities and it was not surprising that basic ASRH services were not provided as most of the health care providers had no training on ASRH and therefore lack skills and competencies in SRH service delivery for adolescents. Overall, ASRH availability space and equipment, availability of ASRH services, appropriate ASRH service delivery and quality of ASRH services were suboptimal across the three senatorial zones in Plateau State.

\section{Abbreviations}

PHC Primary Health Care

ASRH Adolescent Sexual and Reproductive Health

SRH Sexual and Reproductive Health

LGA Local Government Area

STI Sexually Transmitted Infection

VCT Voluntary Counselling and Testing

GBV Gender Based Violence

HF Health Facility

\section{Declarations}

\section{Declaration of Conflicting Interests}

The authors declared no conflicts of interest whatsoever with the conduct of the research, the authorship and the publication of this article.

\section{Consent for publication:}

Not Applicable

\section{Data}

The raw data is provided as a supplementary materials here

\section{Funding:}

The research was self-sponsored and authors did not receive any support for research or publication from any source

\section{Authors' contribution:}

EAE conceptualized and design the research, wrote the proposal, was part of data collection, data analysis/interpretation of data and manuscript write up. KM read and contributed to the proposal, directed and corrected the data analysis, reviewed and contributed to the 
manuscript write up. JDW was part of the conceptualization and design of the research, read and corrected the proposal, supervised and corrected the data interpretation and directed and revised the manuscript write up

\section{Acknowledgement:}

Not application

\section{References}

1. 10.11604/pamj.2017.26.103.11436

Ahmed ZD, Sule IB, Abolaji ML, Mohammed Y, Nguku P. Knowledge and utilization of contraceptive devices among unmarried undergraduate students of a tertiary institution in Kano State, Nigeria.Pan Afr Med J. 2017 Feb 28;26:103. doi: 10.11604/pamj.2017.26.103.11436. eCollection 2017.

2. Ajide KB, Balogun FM. Knowledge of HIV and Intention to Engage in Risky Sexual Behaviour and Practices among Senior School Adolescents in Ibadan, Nigeria. Arch Basic Appl Med. 2018;6(1):3-8.

3. Onyeka IN, Miettola J, llika AL, Vaskilampi T. Unintended Pregnancy and Termination of Studies among Students in Anambra State, Nigeria. African Journal of Reproductive Health. 2011;15:109.

4. Aboki H, Folayan MO, Daniel U, Ogunlayi M. Changes in Sexual Risk Behaviour Among Adolescents: Is the HIV Prevention Programme in Nigeria Yielding Results? Afr J Reprod Health. 2014;18(3):109-17.

5. Nwabueze SA, Azuike EC, Ezenyeaku CA, Aniagboso CC, Azuike ED, lloghalu IC, et al. Perception of Sexually Transmitted InfectionPreventive Measures among Senior Secondary School Students in Nnewi-North Local Government Area, Anambra State, Nigeria. Open Journal of Preventive Medicine. 2014;4:708-16.

6. Hindin MJ, Fatusi AO. Adolescent sexual and reproductive health in developing countries: an overview of trends and interventions. IntPerspect Sex Reprod Health. 2009;35(2):58-62.

7. Jonas K, Crutzen R, van den Borne B, Sewpaul R, Reddy P. Teenage pregnancy rates and associations with other health risk behaviours: a three-wave cross-sectional study among South African school-going adolescents. BMC Reprod Health. 2016;13(1):50. https://doi.org/10.1186/s12978-016-0170-8.

8. Ssebunya RN, Matovu JKB, Makumbi FE, Kisitu GP, Maganda A, Kekitiinwa A. Factors associateed with prior engagement in high-risk sexual behaviours among adolescents (10-19 years) in a pastoralist post-conflict community, Karamoja sub-region, North eastern Uganda. BMC Public Health. 2019;19:1027. https://doi.org/10.1186/s12889-019-7352-.

9. Kassa GM, Arowojolu AO, Odukogbe AA, Yalew AW. Prevalence and determinants of adolescent pregnancy in Africa: a systematic review and Meta-analysis. Reprod Health. 2018;15:195. doi:10.1186/s12978-018-0640-2.

10. Afolaranmi TO, Hassan ZI, Akinyemi OO, Oluwakayode AJ, Oluchukwu UC, Rotimi AP, Chingle MP. Adolescent Pregnancy: An Assessment of a Rural Community in Plateau State, North Central Nigeria. International Journal of Biomedical Research. 2017;8(06):344-8.

11. Mmari KN, Oseni O, Fatusi AO. STI Treatment-Seeking Behaviours Among Youth in Nigeria: Are There Gender Differences. International Perspectives on Sexual Reproductive Health. 2010;36(2):72-9.

12. Munakampe MN, Zulu JM, Michelo C. Contraception and abortion knowledge, attitudes and practices among adolescents from low and middle-income countries: a systematic review. BMC Health Services Research. 2018;18:909.

13. Aliyu AA, Dahiru T, Ladan AM, Shehu AU, Abubakar AA, Oyefabi AM, Yahaya SS. Knowledge. Sources of information, and Risk Factors for Sexually Transmitted Infections among Secondary School Youth in Zaria, Northern Nigeria. J Med Trop. 2013;15:102-6.

14. NAIDS. HIV prevention among adolescent girls and young women. 2016. Available from:http://www.unaids.org/sites/default/files/media_asset/UNAIDS_HIV_prevention_among_adolescent_girls_and_young_women.pdf, Last accessed 17/7/2019.

15. Hidayana IM, Noor IR, Benedicta GD, Prahara H, Zahro FA, Kartikawati R, Hana F. Pebriansyah, Kok MC.Factors Influencing Child Marriage, Teenage Pregnancy and Female Genital Mutilation/Circumcision in Lombok Barat and Sukabumi Districts, Indonesia.

16. Tayo A, Akinola O, Babatunde A, Adewunmi A, Osinusi D, Shittu L. Contraceptive knowledge and usage amongst female secondary school students in Lagos, Southwest Nigeria. J Public Health Epidemiol. 2011;3:34-7.

17. Ayuba II, Gani O. Outcome of Teenage Pregnancy in the Niger Delta of Nigeria. Ethiop J Health Sci. 2012;22(1):45-50.

18. World Health Organization (WHO). Maternal, newborn, child and adolescent health.

http://www.who.int/maternal_child_adolescent/topics/maternal/adolescent_pregnancy/en/. Accessed 14 Apr 2016. 
19. Schwandt HM, Speizer IS, Corroon M. Contraceptive service provider imposed restrictions to contraceptive access in Urban Nigeria. BMC Health Services Research. 2017;17:278.

20. Odo AN, Samuel ES, Nwagu EN, Nnamani PO, Atama CS. Sexual and reproductive health services (SRHS) for adolescents in Enugu state, Nigeria: a mixed methods approach. BMC Health Services Research. 2018;18:92.

21. Durowade KA, Babatunde OA, Omokanye LO, Elegbede OE, Ayodele LM, Adewoye KR, Adetokunbo S, Olomofe CO, Fawole AA, Adebola OE, Olaniyan TO. Early sexual debut: prevalence and risk factors among secondary school students in Ido-ekiti, Ekiti state, South-West Nigeria. Afri Health Sci. 2017;17(3):614-22. https://dx.doi.org/10.4314/ahs.v17i3.3.

22. Federal Ministry of Health (Nigeria). National strategic framework on the health \& development of adolescents \& young people in Nigeria. Abuja, Nigeria; 2011. Accessed:30 June 2019.

23. Envuladu EA, Anke Van de Kwaak, Zwanikken P, Zoakah Al. Exploring the Factors Influencing Adolescent Sexual Behavior in Plateau State Nigeria. American Journal of Medicine Medical Sciences. 2017;7(1):1-6.

24. WHO. Global standards for quality health-care services for adolescents: a guide to implement a standard -driven approach to improve the quality of health care services for adolescents. Geneva: World health Organization; 2015.

25. Cochran WG. Sampling techniques. 3rd ed. New York: John Wiley \& Sons; 1977.

26. Sreekumar S, Ramakrishnan J, Harisankar D, Mannethodi K. Felt needs and expectations of adolescents regarding sexual and reproductive health from schools and health systems: A descriptive study. Indian J Sex Transm Dis AIDS. 2019;40(1):30-4. doi:10.4103/ijstd.IJSTD_20_17.

27. WHO. Global Health Estimates (GHE), 2016.

28. Baseline report YES I DO. 2016. Available at https://www.kit.nl/wp-content/uploads/2018/10/Baseline-report-Indonesia-Yes-I-Do.pdf. Last accessed 11/11/2019.

29. Shamagonam James PT, Pisa J, Imrie* MP, Beery C, Martin, Catherine Skosana and Sinead Delany-Moretlwe. Assessment of adolescent and youth friendly services in primary healthcare facilities in two provinces in South Africa. BMC Health Services Research. 2018: 18:809. https://doi.org/10.1186/s12913-018-3623-7.

30. Mmari KN, Magnani RJ. Does making clinic-based reproductive health services more youth-friendly increase service use by adolescents? Evidence from Lusaka, Zambia. J Adolesc Health. 2003;33(4):259-70.

31. Birhanu Z, Tushune K, Jeben MG. Sexual and Reproductive Health Services Use, Perceptions, and Barriers among Young People in Southwest Oromia, Ethiopia. Ethiop J Health Sci. 2017;28(1):37. doi:http://dx.doi.org/10.4314/ejhs.v28i1.6.

32. Kyilleh JM, Tabong PT, Konlaan BB. Adolescents' reproductive health knowledge, choices and factors affecting reproductive health choices: a qualitative study in the West Gonja District in Northern region, Ghana. BMC Int Health Hum Rights. 2018;18(1):6. doi:10.1186/s12914-018-0147-5.

33. Stanzel KA. Outreach youth health service in school setting: a retrospective case study. Aust J Prim Health. 2016;22(3):185-9. doi:10.1071/PY15121.

34. Copen CE, Dittus PJ, Leichliter JS. Confidentiality Concerns and Sexual and Reproductive Health Care Among Adolescents and Young Adults Aged 15-25. NCHS Data Brief. 2016;(266):1-8.

35. Subedi R, Jahan I, Baatsen P. Factors Influencing Modern Contraceptive Use among Adolescents in Nepal. J Nepal Health Res Counc. 2018;16(3):251-6.

\section{Supplementary Files}

This is a list of supplementary files associated with this preprint. Click to download.

- hEALTHFACILITYDATA.sav

- HEALTHFACILITYQUESTIONNAIRE.docx 